Brit. Heart f., 1967, 29, 636.

\title{
Fifth World Congress of Cardiology
}

In the impressive auditorium of the Vygian Bavan the Fifth World Congress of Cardiology was opened in New Delhi on November 30, 1966. Cardiologists, many with their wives, had converged upon the city in weather that was warm but not oppressive. At the opening ceremony, participants were honoured by the presence of the President of India, Dr. S. Radhakrishnan who, in his address, underlined the importance of cardiology not only as a vast clinical specialty but also in relation to world health. Dr. K. K. Datey, President of the Congress, in a gracious speech, foreshadowed the work of the Congress and referred to the opportunity members would have of learning something of the heritage of India and seeing other parts of the land.

The Fifth World Congress was acclaimed on all sides as an unqualified success. This was the result of long and exacting preparation by the President, Dr. K. K. Datey, and by the Secretary General, Dr. S. Padmavati. Their thoughtfulness for the comfort and enjoyment of visitors, their hospitality to members of the Congress, and their success in the day-to-day running of the scientific meetings, were deeply appreciated. Wives and families of participants were entertained.

At meetings of the Council and the General Assembly some important decisions were made. Sir Kempson Maddox was elected President of the International Society in succession to Dr. Pierre Duchosal who had conducted the affairs of the Society with outstanding success. In the scientific field, far-sighted developments were planned. Basically, the Society has been grouped into eight sections: atherosclerosis and ischæmic heart disease, clinical and electro-physiology, epidemiology and preventive cardiology, hypertension, rehabilitation, cardiomyopathies, and pædiatric cardiology. Each section will be responsible for co-ordinating, on a world-wide basis, research, training, and education in its own particular discipline. From Britain, M.F. Oliver of Edinburgh, and Hamish Watson of Dundee, were appointed as heads of the section of atherosclerosis and pædiatric cardiology, respectively.

A symposium, which had been planned with much care and forethought, was held each morning. In general these were highly successful and provoked useful discussions. No simultaneous meeting was held during these occasions and the result was an auditorium filled almost to capacity with none of the interchange or attenuation of audience that can be so distracting to speaker and hearer alike. Some of the meetings in subsidiary halls in the afternoon attracted much larger audiences than were expected, and on a few of these occasions even standing room was limited. The system of multiple small afternoon meetings had the advantage of more informal discussion, but inevitably meant that some good papers were given simultaneously. The need to accept enough contributions to satisfy national aspirations, and at the same time avoid overcrowding of sessions, and too many simultaneous sessions, is an everrecurring difficulty for congress organizers and will present increasing problems for those who plan for future congresses.

Notable among the many worth-while contributions were the session allotted to the assessment by physicians of the effects of cardiac surgery, the paper on treatment of tricuspid defects at mitral valve replacement and in Ebstein's disease, and a good double-blind study showing no effect from the use of anticoagulants in myocardial infarction. Papers on the surgery of heart disease showed the improved operative results in transposition, and discussed the place of total correction in the tetralogy of Fallot and the value of corrective operations on the mitral and aortic valves.

The Congress was notable for the lavish entertainments offered to visitors. Performances of national music and dancing and of ballet in the open air were unforgettable, and on a more personal scale the many garden parties and evening functions provided relaxation from the arduous professional work. Outstanding was the Congress evening party held under the vast and resplendent shamiana. Concourses on this scale are in a different category from the meetings of small groups of experts to discuss a defined problem; the latter deal more with the growing points in cardiological science, while the former foster international friendships as well as providing a survey of cardiological work in a great variety of disciplines, and are valuable for those whose work takes them more to the bedside 
than to the laboratory. It is hoped that our members will attend congresses in increasing numbers. Those who feared a ducking in the overloaded pleasure boat in Prague, and those who almost slipped with the howdah under the belly of the elephant at Jaipur, not to mention those who emerged from almost knee-deep mud in the Arctic Circle will look back to those days with affection if not with nostalgia. For some the conclusion of the
Congress was the starting point of visits to Ceylon or Rajasthan; others converged upon New Delhi after travelling in Nepal or Kashmir. For all, there will be indelible memories of the warm welcome of our hosts, the reunion of old friends, and the innumerable and vivid impressions made by this land, with its heritage of ancient art and culture.

K. SHIRLEY SMITH 